UIITED STATES DEPARTMENT OF THE INTERIOR GEOLOGICAL SURVEY

A STUDY OF CRITICAI FACTORS III THE "DIRECT" FLUORIMETRIC DETERMTNATION OF URANIUM

Mary H. Fletcher

October 1950

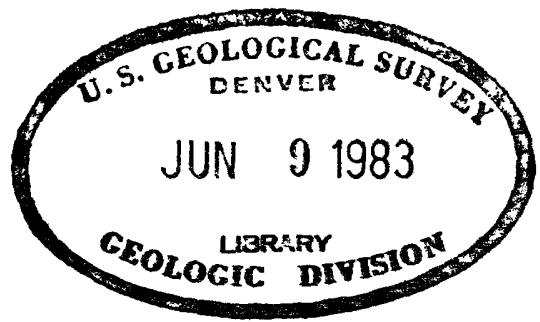

Trace Elements Investigations Report 130 
USGS-TEIR 130

Consisting of 28 pages

Issued to (see below)

The distribution of this report is as follows:

2 copies ...................AEC, Washington (J. C. Johnson)

8 copies ................. AEC, Hew York ( $P$. L. Merritt)

1 copy.$\ldots \ldots \ldots \ldots \ldots \ldots \ldots \ldots A E C$, Washington (J. O. Hosted)

1 copy ....................AEC, Denver (C. C. Towle, Jr. )

1 copy.$\ldots \ldots \ldots \ldots \ldots \ldots \ldots \ldots$ AEC, Spokane (E. E. Thurlow)

'I copy ................... AEC, Grand Junction (T. W. Oster)

I copy ................... IMCC, Mulberry, Fla. (I. M. LeBaron)

1 copy .................. Dow Chemical Co., P1ttsburg, Calif. (G. L. Allen)

1 copy ......................MIT, Watertown, Mass. (John Dasher)

1 copy .................... ORNL, Y-12, Oak R1dge (Glenn Clewett)

1 copy ................... USGS, Washington (Mineral Deposits Branch)

I copy .................... USGS, Washington (Fuels Branch)

I copy..$\ldots \ldots \ldots \ldots \ldots \ldots \ldots$ USGS, Washington (Alaskan Branch)

I copy .................. USGS, Washington (Geophysics Branch)

20 copies ............... USGS, Washington (Geochemistry and

1 copy ................... USGS, Washington (V. E. McKelvey)

1 copy .................. USGS, Plant City, Fla. (J. B. Cathcart)

1 copy .................. USGS, Grand Junction (R. P. Fischer)

1 copy ................... USGs, Denver (L. R. Page)

I copy ................... USGS, Spokane (A. E. Welssenborn)

4 copies .................. USGS, Washington (TEPCO)

(including master copy) 
Abstract $\ldots \ldots \ldots \ldots \ldots \ldots \ldots \ldots \ldots \ldots \ldots \ldots \ldots \ldots \ldots \ldots \ldots \ldots \ldots \ldots \ldots \ldots \ldots \ldots$ I

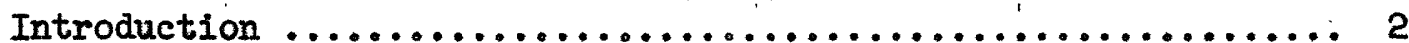

Acknowledgments ............................... 5

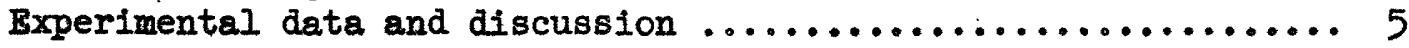

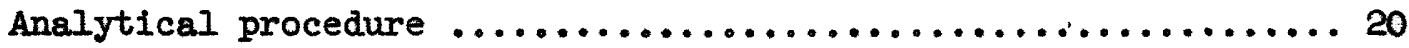

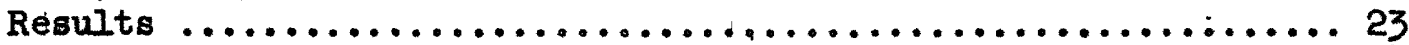

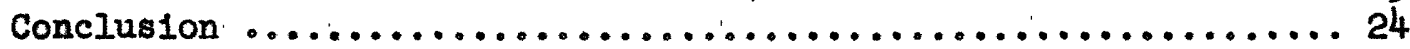

IILUSTRATIONS

Following

page

Figure 1. Effect of fusion conditions on fluorescence of blank samples ....................... 8

2. Effect of fusion conditions on fluorescence of standard samples ...................... 8

3. Effect of fusion conditions on sensitivity ........ 8

4. Assembly--Model II transmission fluorimeter ........ 20

5. Model II transmission fluorimeter ...............20

6. Bquipment ............................ 20

TABIES

Page

Table 1. Attack on platinum lid by flux as a function of fusion temperature ............... 9

2. Summary of time-temperature study for blanks ........ 10

3. Summary of time-temperature study for

standard samples ...................... II

4. Effect of fusion conditions on sensitivity ........ 12

5. Reproducibility of fluorescence of blanks heated in a small furnace ................. 16

6. Reproducibility of fluorescence of blanks heated in a large furnace .................. 17

7. Inadequacy of fusion mixture prepared by bell-milling .............................. 19

8. Replicate analyses of standard shale sample GST-1 ... 25

9. Replicate analyses of standard shale sample GST-2 ... 26

10. Comparison of results obtained by different methods of analysis of northwest phosphates ...........27

11. Determination of uranium by the "direct" method using different aliquots ..................28 


\title{
A STUDY OF CRITICAL FACTORS IN THE "DIRECT" FLUORIMETRIC DETERMINATION OF URANIUM
}

\author{
Mary H. Fletcher
}

\begin{abstract}
A study was made of the important factors in the "direct" fluorimetric determination of uranium in the range 0.0005 to 0.08 micrograms of uranium, and a modified procedure based on these results is given. Detailed time-temperature studies showed that the sensitivity of the fluorescent method decreased rapidly when the fusion temperature was greater than $650^{\circ} \mathrm{C}$, and that at temperatures above $650^{\circ} \mathrm{C}$. the sensitivity decreased with increased time of heating. Inhomogeneity of the carbonate fluoride flux led to erratic results.

Highly reproducible results were obtained by fusing at $650^{\circ} \mathrm{C}$. for 25 minutes, using a carbonate fluoride flux that had been fused and then ground. Phosphors prepared by this procedure are reproducible to about \pm 5 percent day after day, thus allowing the use of a permanent standard curve. Standard samples are unnecessary once the standard curve has been prepared.
\end{abstract}




\section{INIRODUCTION}

Many of the chemical laboratories that analyze large numbers of sampies for traces of uranium use a "direct" fluorimetric method for many of the determinations. By "direct" fluorimetric method, it is understood that the sample or sample aliquot is fused with sodium fluoride or an alkali carbonate fluoride mixture, and that the fluorescence of the melt is measured. The use of Price's "dilution technique" $I$ / and the development of extremely sensitive fluorimeters $1,2,3,4,5,6,7 /$ have eliminated ilmost entirely the necessity for chem1cal separations. Although the manipulative details and the equipment used in the different laboratories differ, the general method for the "direct" determination of uranium has been well established.

\section{I/ Price, G. R., Ferrett1, R. J., 8chwartz, Samuel, The micro-} fluorimetric determination of uranium: AECD-2282, July 1945.

2) Fletcher, Nary H., Nay, Irving, and slavin, Morris, A transmission fluorimeter for use in the fluorimetric method of analysis for uranium: U. 8. Geol. Survey Trace Elements Investigations Rept. 104, August 1949.

3/ Fletcher, Mary H., May, Irving, and Anderson, Joseph W.; The design of the Model $v$ transmission fluorlmeter: U. S. Geol. Survey Trace Elements Investigations Rept. 133, December 1950.

4/ May, Irving, and Fletcher, Mary H., A battery-powered fluorimeter for the determination of uranium: U. S. Geol survey Trace Elements Investigations Rept. 135, December 1950.

5/ Pickel, C. B., AECD-2433, October 1946.

6/ Price, G. R., Ferretti, R. J., and Schwartz, Samuel, The · design and construction of sensitive fluorphotometers--Part I. principles: All-4113, April 1948.

If Bmith, S. B., and Ne11, H. G., Y-407, January 1946. 
All of the instruments referred to, and perhaps others, have greater sensitivity than can be used to full advantage. At present, the size and reproducibility of the blanks set the lower sensitivity 11mit. The errors that occur in readings of replicate blanks or standards usually are greater than the instrumental error, which may be measured by replicate readings on a single blank or standard. At this time therefore, further improvement of instrumental sensitivity or precision should be secondary to the production of more reproducible phosphors and to obtaining a fusion mixture that will give lower blank readings.

In setting up a standard procedure for the "direct" determination of uranium in this laboratory, it was desired to find a method of phosphor preparation that was reproducible day after day, and one that would allow for the duplication of the fluorescence to \pm 5 to 10 percent for melts of any given uranium content. Such a phosphor would make it unnecessary to fuse standards with each batch of unknowns. One standard curve could be prepared and used permanently with only infrequent checks, as for example when a new batch of flux was prepared. A transmission fluorimeter 8 / was chosen for the measurement of the fluorescence. This instrument is set to a "standard deflection" which is a measure of filter leakage; therefore, once the standard curve is prepared, standard samples of any kind are unnecessary.

8/ Fletcher, Mary H., May, Irving, and Slavin, Morris, A transmission fluorimeter for use in the fluorimetric method of analysis for uranium: O.S. Geol. Survey Trace Elements Investigations Rept. 104, August 1949 . 
Several investigators have reported the effects of different methods of heating on the fluorescence of fluoride melts. Some have pointed out the variations in results which occur when the fusions are made in oxidizing as contrasted to reducing atmospheres, 9 / or at high temperatures as contrasted with lower temperatures, 10/ or in atmospheres of various gases.11/ 0thers 12,13,14/ have stated that fusions with a similar flux should not be made at temperatures greater than $750^{\circ} \mathrm{C}$. because of the solution of platinum at higher temperatures. Early work in the U. S. Geological survey laboratory indicated that temperature, period of fusion, and homogeneity of flux were the most important factors affecting the reproducibility of the method. It was believed that a homogeneous flux could be prepared by fusion of the ingredients, followed by grinding and mixing, and that furnace fusions at controlled temperatures for a standard length of time would

9/ Grimes, W. R., and Clark, F. E., H.1.740.10-Clinton Eng. Works, Tenn. Eastman Corp., May 1948.

10/ Simpson, S. D., The photofluorometric determination of uranium: Nat. Research Council--Atomic Energy Project--Chalk River, Ontario, Canada-R.M.C. 14 (Abstract No. 26) or No. 263/26 (paper presented at the London Conference).

Il/ Price, G. R., Ferrett1, Renato J., and Schwartz, Samuel, ANL- 4002 and addenda, Apr11 1947.

12/ Bartlett, T. W., Lasko, W., Wiberly, S. F., Coleman, C. F. and Orelemann, E. F., Fluorescent methods: T.B.C.C-4.100.19, p. 9, August 1945.

13/ C.E.W. Tenn. Eastman Corp., Div. of Chem. Research and Development Anal. Div. P.P.R. perlod ending July 1945, Document C.4.360.1I Series A, p. 38, 1945.

14/Grimaldi, F. S., and Levine, Harry, The rapid fluorimetric determination of uranium in low-grade ores; a preliminary report: U. S. Geol. Survey Trace Elements Investigations Rept. 47, April 1948. 
give reproducible phosphors. These ideas proved to be correct, and a satisfactory method has been found for the preparation of reproducible phosphors. Quenching by platinum dissolved from the fusion vessel by the flux is believed to have been the chief cause for nonreproducibility in earlier work. Controlled low-temperature fusions practically eliminate this error.

\section{Acknowledgments}

The author is indebted to many of her colleagues in the Geological Survey for valuable suggestions and assistance durlng the course of this work. She is especially indebted to Karl Kozee and Melvin Hanes who prepared the drawings and graphs, to E. B. Templeman who made the photographs, and to John C. Rabbitt, Michael Fleischer, F. S. Grimaldi, and Jane Titcomb who reviewed this paper and made many suggestions.

EXPERIMEINTAL DATA AND DISCUSSION

Many substances were considered, and several mixtures were tested before the final choice of a fusion mixture was made. A one-component flux such as NaF should be ideal for homogeneity: hovever, this substance has a very high melting point, and where used alone adheres strongly to the platinum fusion vessel. Several different mixtures of $\mathrm{NaF}$ and $\mathrm{Na}_{2} \mathrm{CO}_{3}$ were tested, and either they had a tendency to stick to the fusion vessel or they gave discs that were too fragile. The three-component mixtvre used by Grimaldi and Levine 15/ had the requisite 15/ Grimaldi, F. S., and Levine, Harry, Personal communication. 
physical characteristics. The composition of this flux is 9 parts of $\mathrm{NaF}, 45.5$ parts of $\mathrm{Na}_{2} \mathrm{CO}_{3}$, and 45.5 parts of $\mathrm{K}_{2} \mathrm{CO}_{3}$ by weight. To remove any uncertainty concerning the uniformity of the fusion mixture, a large batch was prepared by fusing the ingredients in a platinum vessel, hand-grinding the cool melts in a mullite mortar, and then thoroughly mixing the combined batches by rolling on a mixing cloth.

The melting point of this flux was determined by the standard method of making melting and cooling curves. The mixture started to melt at $575^{\circ} \mathrm{C}$. and was completely molten at $605^{\circ} \mathrm{C}$. On cooling, the flux started to solidify at $605^{\circ} \mathrm{C}$. and seemed to be completely solidified at $575^{\circ} \mathrm{C}$. No sharp break was observed in either curve. The fusion was made in a J. I. Smith crucible which was heated in a small electric pot furnace. The temperatures were determined by measuring the voltage which developed in a platinum-platinum + rhodium thermocouple placed in the molten material.

For the time-temperature studies, replicate blank samples and standard samples containing 0.005 micrograms of uranium were fused with $1.5 \mathrm{~g}$ of flux in the platinum lids of 25-ml crucibles. The fusions were made at $800^{\circ}, 750^{\circ}, 700^{\circ}, 650^{\circ}$, and $620^{\circ} \mathrm{C}$. for various intervals of time. Two to four replicates were made for each period at each temperature. The fusions were made in a small muffle furnace which accommodated two lids at a time; the melts were mixed by swirling them about three times during the fusion period. The furnace temperature was controlled at the higher temperatures by manual operation of a rheostat; for the tests made at $650^{\circ}$ and $620^{\circ} \mathrm{C}$. the temperature was 
regulated with an automatic controller. When the lids were removed from the furnace, they were held by tongs until the melts crystallized. They were then cooled in a desiccator for 30 minutes before the fluorescence was measured.

The group of melts fused at $800^{\circ} \mathrm{C}$. and also that group fused at $750^{\circ} \mathrm{C}$. each formed a graduated color series when compared under white light. The melts of each group increased in yellowness with the length of the fusion period; those fused at $800^{\circ} \mathrm{C}$. were darker yellow then the corresponding melts fused at $750^{\circ} \mathrm{C}$. For example, the yellowness of a melt fused at $800^{\circ} \mathrm{C}$. for 3 minutes corresponded to that of a melt fused at $750^{\circ} \mathrm{C}$. for 10 minutes; and the fluorescence of these two phosphors also was comparable. The melts that were fused for 5 to 10 minutes at $800^{\circ}$ and $750^{\circ} \mathrm{C}$. showed a decided murkiness just before they solidified; however, when the melts were removed from the lids in which they were fused, the lids were relatively clean. By way of contrast, even 40-minute fusions at $650^{\circ} \mathrm{C}$. and lower gave melts that appeared to be perfectly white but the lids used for these fusions showed a dark stain. This stain increased with the length of the fusion and was very heavy after the 20- and 40-minute fusions. At temperatures of $650^{\circ} \mathrm{C}$. and less, the platinum lid seemed to be attacked, but only a small part dissolved in the melt.

The degree of attack on the lid by the flux was determined for fusions made at different temperatures. Samples of a fusion mixture weighing $1.5 \mathrm{~g}$ each were fused for 10 minutes in the small furnace. One portion was fused at $650^{\circ} \mathrm{C}$., one at $700^{\circ} \mathrm{C}$, , one at $750^{\circ} \mathrm{C}$, one at 
$800^{\circ} \mathrm{C}$, and also two were fused at $800^{\circ} \mathrm{C}$. and then re-fused for an additional 10 minutes at $650^{\circ} \mathrm{C}$. The melts were dissolved in a little water and hydrochloric acid, and the solutions evaporated to dryness. The residues then were dissolved in water and analyzed for platinum by the stannous chloride colorimetric method.16/ The standards used for comparison contained 1.5 grams of fusion mixture treated in the same manner. The lids that were used for these fusions were boiled with 50 percent hydrochloric acid until the stain seemed to have disappeared. The lids then were removed and the solutions evaporated to dryness. Platinum was determined on these residues by the same colorimetric method except that a new set of standards which contained no fusion mixture was used for comparison. The density measurements were made at $420 \mathrm{m \mu}$ with a Beckman spectrophotometer.

The results of these analyses are given in table 1 . It will be seen that the platinum content of the melts is a direct function of the fusion temperature.

The results of the time-temperature study have been summarized in graphs. Figure $I$ shows the fluorescence of blanks plotted against total time in the furnace at different temperatures. Figure 2 shows the same for standard samples which contained 0.005 micrograms of uranium. In figure 3 the data presented in figures $I$ and 2 are combined and the sensitivity is plotted against total time in the furnace at varlous temperatures. Tables 2,3 , and 4 present the data from which these graphs were prepared.

16/ Sandell, E. B., Colorimetric determination of traces of metals, New York, Interscience Publishers, Inc., p. 358, 1944. 


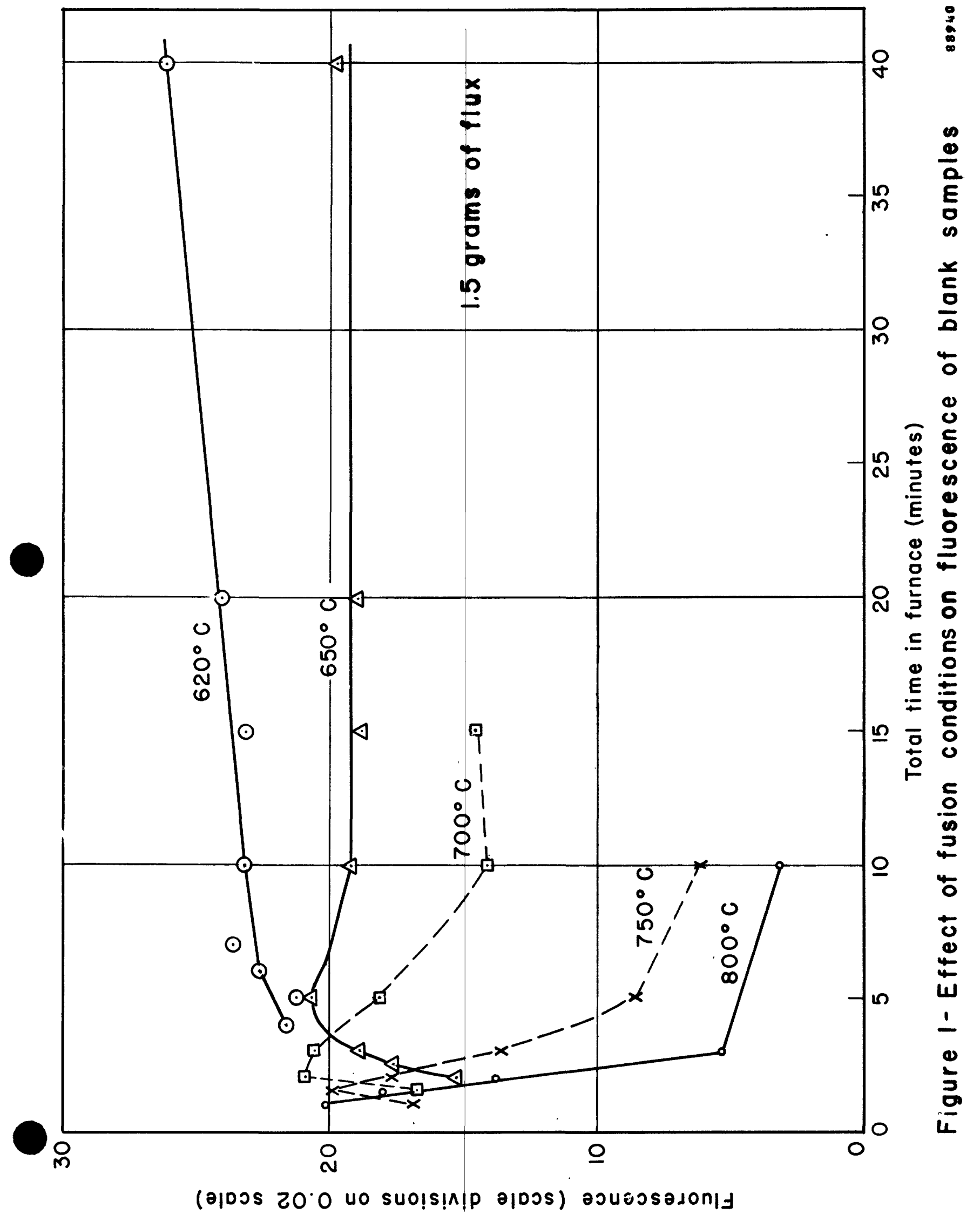




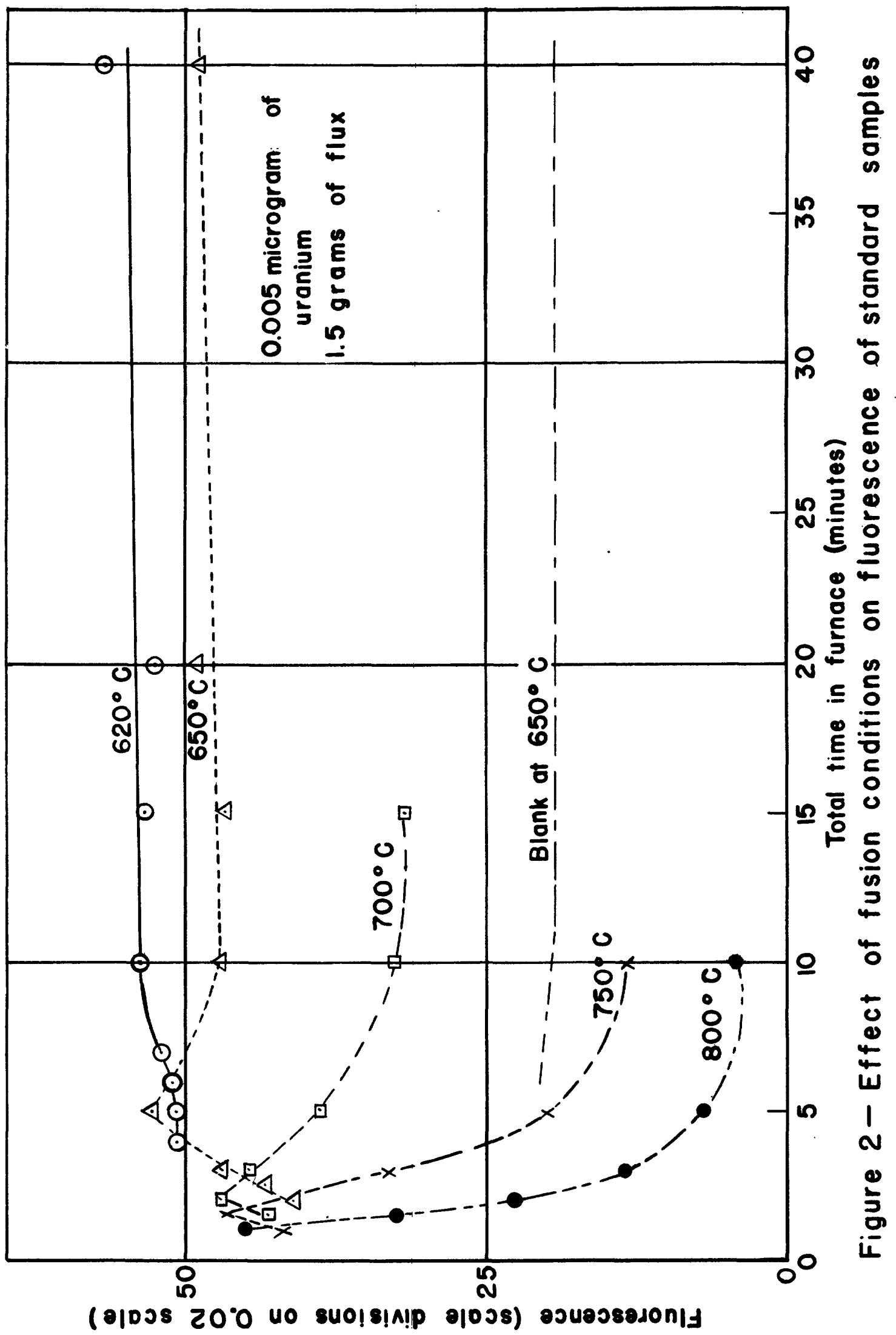




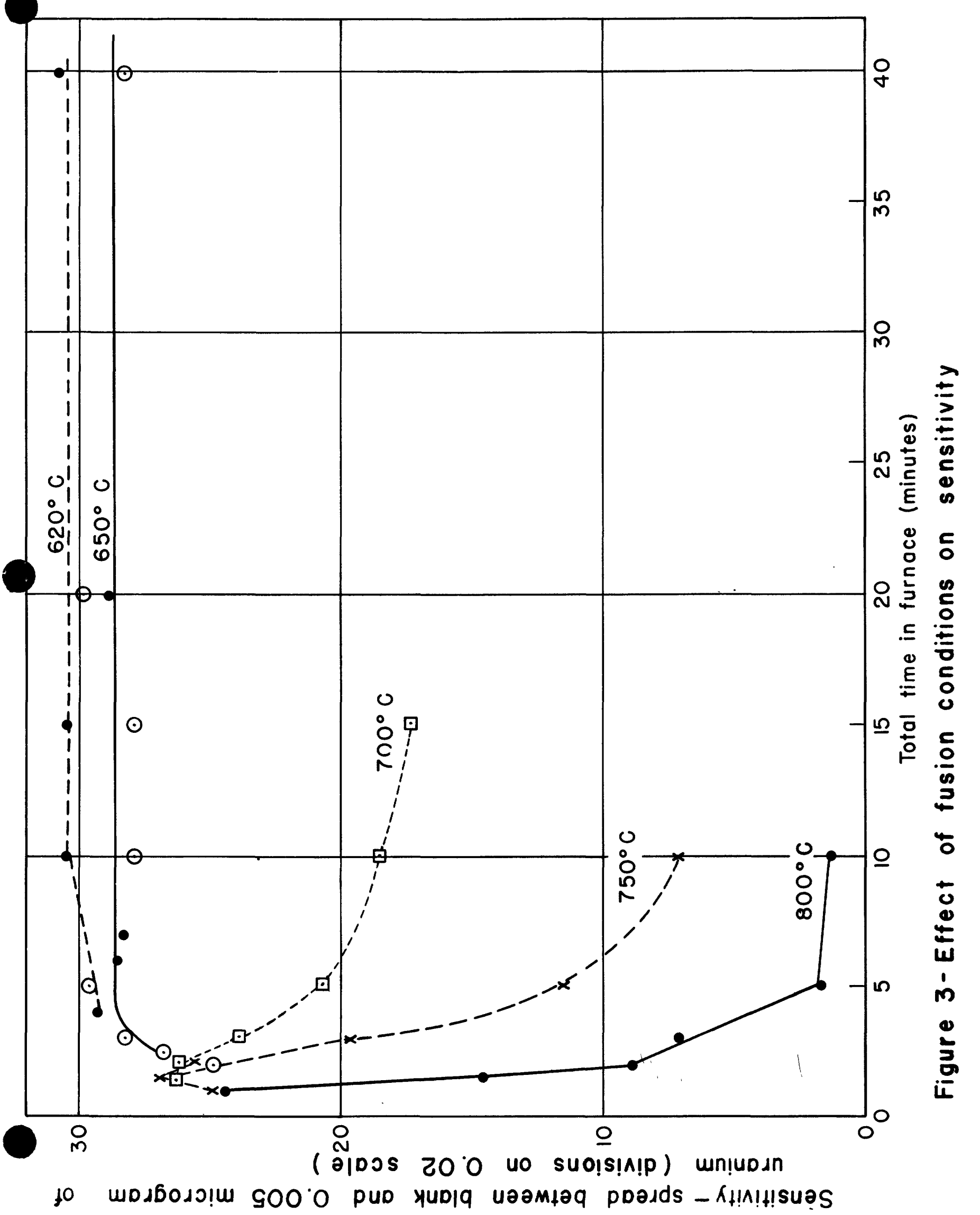


Table 1.- Attack on platinum lia.by flux as a function of fusion temperature.

(10-minute fusion in small furnace)

\begin{tabular}{c|c|c}
\hline \multirow{2}{*}{$\begin{array}{c}\text { Temperature of fusion } \\
\text { (degrees centigrade) }\end{array}$} & \multicolumn{2}{|c}{ Micrograms of platinum found } \\
\cline { 2 - 3 } 650 & in melts & on 1ids I/ \\
700 & 33 & 156 \\
750 & 76 & 113 \\
800 & 155 & 148 \\
$8002 /$ & 174 & 125 \\
$8002 /$ & 174 & 218 \\
\hline
\end{tabular}

I/ Soluble in $\mathrm{BCl}$

2/ Re-fused for an additional 10 minutes at $650^{\circ} \mathrm{C}$. 
Table 2.--Sumary of time-temperature study for blanks ( 1.5 grams of flux)

\begin{tabular}{c|c|c|c|c|c}
\hline \multirow{2}{*}{$\begin{array}{c}\text { Total time } \\
\text { in furnace } \\
\text { (minutes) }\end{array}$} & \multicolumn{5}{|c}{ Average readings-divisions on 0.02 scale } \\
\cline { 2 - 6 } & $800^{\circ} \mathrm{C}$. & $750^{\circ} \mathrm{C}$. & $700^{\circ} \mathrm{C}$ & $650^{\circ} \mathrm{C}$. & $620^{\circ} \mathrm{C}$. \\
\hline 1 & 20.5 & 16.8 & - & - & - \\
$1 \frac{3}{2}$ & 18.0 & 19.9 & 16.7 & - & - \\
2 & 13.8 & 17.6 & 20.9 & 15.2 & - \\
$2 \frac{3}{2}$ & - & - & - & 17.6 & - \\
3 & 6.6 & 13.5 & 20.6 & 18.8 & - \\
4 & - & - & - & - & 21.6 \\
5 & 5.3 & 8.5 & 18.0 & 20.7 & 21.2 \\
6 & - & - & - & - & 22.6 \\
7 & - & - & - & - & 23.6 \\
10 & 3.2 & 6.1 & 14.1 & 19.1 & 23.2 \\
15 & - & - & 14.6 & 18.8 & 23.1 \\
20 & - & - & - & 18.9 & 24.0 \\
40 & - & - & - & 19.7 & 26.1 \\
\hline
\end{tabular}


Table 3.--Summary of time-temperature study for standard samples (0.005 microgram of uranium in $1.5 \mathrm{~g} f l u x)$

\begin{tabular}{|c|c|c|c|c|c|}
\hline \multirow{2}{*}{$\begin{array}{l}\text { Total time } \\
\text { in furnace } \\
\text { (minutes) }\end{array}$} & \multicolumn{5}{|c|}{ Average readings-divisions on 0.02 scale } \\
\hline & $800^{\circ} \mathrm{C}$ & $750^{\circ} \mathrm{C}$ & $700^{\circ} \mathrm{C}$. & $650^{\circ} \mathrm{C}$. & $620^{\circ} \mathrm{C}$ \\
\hline 1 & 45.0 & 41.7 & - & - & - \\
\hline $1 \frac{1}{2}$ & 32.6 & 46.7 & 42.9 & - & - \\
\hline 2 & 22.7 & 43.2 & 47.0 & 40.1 & - \\
\hline $2 \frac{1}{2}$ & - & - & - & 43.3 & - \\
\hline 3 & 13.7 & 33.1 & 44.5 & 47.0 & - \\
\hline 4 & - & - & - & - & $50.9=$ \\
\hline 5 & 7.0 & 20.0 & 38.7 & 50.3 & 50.8 \\
\hline 6 & - & - & - & - & 51.1 * \\
\hline 7 & - & - & - & - & 51.9 \\
\hline 10 & 4.5 & 13.3 & 32.6 & 47.0 & 53.7 \\
\hline 15 & - & - & 31.9 & 46.7 & 53.5 \\
\hline 20 & - & - & - & 48.7 & 52.8 \\
\hline 40 & - & - & - & 47.9 & 56.8 \\
\hline
\end{tabular}

* Calculated from readings on 0.05 scale 
Table 4.--Effect of fusion conditions on sensitivity

\begin{tabular}{|c|c|c|c|c|c|}
\hline \multirow{2}{*}{$\begin{array}{l}\text { Total time } \\
\text { in furnace } \\
\text { (minutes) }\end{array}$} & \multicolumn{4}{|c|}{$\begin{array}{r}\text { Spread between blank and } 0.005 \text { microgram } \\
\text { (divisions on } 0.02 \text { scale) }\end{array}$} & \multirow{2}{*}{ of uranium } \\
\hline & $800^{\circ} \mathrm{C}$ & $750^{\circ} \mathrm{C}$ & $700^{\circ} \mathrm{C}$ & $650^{\circ} \mathrm{C}$ & \\
\hline 1 & 24.5 & 24.9 & - & - & - \\
\hline $1 \frac{1}{2}$ & 14.6 & 26.8 & 26.2 & - & - \\
\hline 2 & 8.9 & 25.6 & 26.1 & 24.9 & - \\
\hline $2 \frac{1}{2}$ & - & - & - & 25.7 & - \\
\hline 3 & 7.1 & 19.6 & 23.9 & 28.2 & - \\
\hline 4 & - & - & - & - & 29.3 \\
\hline 5 & 1.7 & 11.5 & 20.7 & 29.6 & 29.6 \\
\hline 6 & - & - & - & - & 28.5 \\
\hline . 7 & - & - & - & - & 28.3 \\
\hline 10 & 1.3 & 7.2 & 18.5 & 27.9 & 30.5 \\
\hline 15 & - & - & 17.3 & 27.9 & 30.4 \\
\hline 20 & - & - & - & 29.8 & 28.8 \\
\hline 40 & - & - & - & 28.2 & 30.7 \\
\hline
\end{tabular}


These graphs and tables show the disastrous effects of uncontrolled heating and the necessity for low-temperature fusions. The fluorescence of alkali carbonate fluoride melts with or without added uranium is affected tremendously by the conditions of the fusion. The fluorescence of individual melts and the sensitivity of the determination decrease with increasing fusion temperature, and with increasing period of fusion when the temperature is greater than $650^{\circ} \mathrm{C}$. For very short fusions (that is, just long enough to melt the flux and quickly mix it) the fluorescence at all temperatures is near the maximm; and for low-temperature fusions, the fluorescence is the same for all periods of fusion provided the maximan has been reached. The graphs indicate that the best fusion conditions are a temperature of $650^{\circ} \mathrm{C}$. for a period of at least 10 minutes in the furnace used for this study.

This furnace is small and the thermocouple not enclosed; as a result, it gives excellent response to the controller. The total variation from the desired temperature was about $8^{\circ} \mathrm{C}$. , and although the furnace cooled when the door was opened, it heated up again almost immediately. This small furnace was ideal for a study such as this where careful temperature control was the principal consideration, but a larger furnace is necessary for analytical purposes when large numbers of samples mast be handled.

The best conditions for fusion in a large furnace are harder to define than are those for a smaller furnace. In a large furnace, there is usually a large temperature gradient from the front to the back of the furnace. There is also an appreciable lag which results in a lower or higher temperature than that at which the controller is set. 
When the door is opened to insert samples or to agitate them, the furnace cools and takes much longer to heat up again than does a small furnace. Therefore, the temperature conditions within each furnace showld be determined. A controller setting should be chosen that will not allow the temperature to rise above $650^{\circ} \mathrm{C}$. Any part of the furnace that is always cooler than $605^{\circ} \mathrm{C}$. cannot be used.

The controller for the large furnace used in this laboratory was set at $650^{\circ} \mathrm{C}$, and $10 \mathrm{lids}$, on two racks in rows of 5 each, were placed in the furnace at one time. The front one-third section of the furnace was too cool to fuse the samples and could not be used. The melts were mixed by shaking the rack three times during the fusion (the melts usually solidified at the end of the period of shaking). A period of 15 to 25 mimates in the furnace was required to obtain reproducible maximam fluorescence in the melts. The 25-minute period finally was adopted as the standard fusion time although some of the data presented were obtained at the shorter period.

Later, the furnace chamber was tested with a Bureau of Standards' chromel-alumel thermocouple used in conjunction with a Brown Portable Potentiometer (Model 1177). The temperature at the position of the back lids varied from $600^{\circ}$ to $630^{\circ} \mathrm{C}$., and at the position of the front Iids from $585^{\circ}$ to $610^{\circ} \mathrm{C}$. About 7 minutes were required to fuse the samples after they were inserted into the furnace; whereas, only $11 / 2$ minutes at $650^{\circ} \mathrm{C}$. and 3 minutes at $620^{\circ} \mathrm{C}$. vere required in the small furnace. The unexpectedly low temperatures in the large furnace and the consequent longer fusion time made necessary the 25-minute fusion 
period required to obtain reproducible fluorescence in the melts. Heedless to say, more efficient temperature control results in better reproduction of the fluorescence of the melts. However, even with the wide variations in temperature which existed in the larger furnace, the reproducibility of the fluorescence was well within tolerable limits. Table 5 gives fluorescence readings on replicate blank samples fused in the small furnace, and table 6 gives readings for fusions made in the large furnace. The average deviation from the mean is 0.6 divisions on the 0.02 scale for the small furnace and 1.2 divisions for the large furnace. One division on the 0.02 scale was equivalent to 0.000144 microgram of urantum.

Tests by Norma Guttag (personal communication) of this laboratory have shown that careful fusions over a Meker burner give results comparable to those obtained in the small furnace. The fusions over a burner were made at the minimum temperature required to melt the flux. The molten material was constantly agitated for about one minute. This procedure is quicker than furnace fusions, but demands that care be taken to prevent over-heating. Analyses of several melts fused in this manner showed 3 to 10 micrograms of platinum.

The best fusion conditions for the preparation of the phosphors having been determined, attention again was directed towards the fusion mixture. Several duplicate blank samples of flux, which was prepared by mixing the components in a ball mill without prior fusion, were fused in the small furnace and their fluorescence measured to determine whether this simpler means could be used for preparing the flux. The readings 
Table 5.--Reproducibility of fluorescence of blanks heated in a small furnace

(fusions made at $650^{\circ} \mathrm{C}$. for 5 minutes)

\begin{tabular}{c|c|c}
\hline Sample no. & Scale reading & Deviation from mean \\
\hline 1 & (divisions on 0.02 scale) & (divisions on 0.02 scale) \\
\hline 2 & 15.5 & 0.8 \\
3 & 15.1 & 1.2 \\
4 & 16.0 & 0.3 \\
5 & 16.0 & 0.3 \\
6 & 16.0 & 0.3 \\
7 & 16.5 & 0.2 \\
8 & 17.7 & 1.4 \\
9 & 15.9 & 0.4 \\
mean & 16.8 & 0.5 \\
\hline 0 & 17.0 & 0.7 \\
\hline
\end{tabular}


Table 6.--Reproducibility of fluorescence of blanks heated in a large furnace

(Controller set for $650^{\circ} \mathrm{C}$; actual temperature fluctuated from $585^{\circ}$ to $630^{\circ} \mathrm{C}$.)

Period of fusion: 15 minutes

\begin{tabular}{c|c|c}
\hline Sample no. & Scale reading & $\begin{array}{c}\text { Deviation from mean } \\
\text { (divisions on 0.02 scale) }\end{array}$ \\
\hline 1 & (divisions on 0.02 scale) & 1.7 \\
2 & 18.0 & 1.3 \\
3 & 20.2 & 0.5 \\
4 & 18.7 & 1.0 \\
5 & 22.1 & 2.4 \\
6 & 21.9 & 2.2 \\
7 & 19.0 & 0.7 \\
9 & 19.8 & 0.1 \\
\hline 10 & 18.6 & 1.1 \\
\hline
\end{tabular}


obtained, the time required to melt the mixture, and the total time in the furnace are given in table 7. Reproducible blanks could not be obtained for this fusion mixture. Its fusibility also was different from that prepared by fusion. The ball-mill variety of flux would start to fuse, but lumps which required a greater length of time to melt usually were present. Sometimes as much as 10 minutes were necessary to obtain complete fusion. Furthermore, many air bubbles formed next to the lid, and it was virtually impossible to get rid of them. In contrast to this, the mixture prepared by fusion always melted in about the same length of time ( 1 to $11 / 2$ minutes at $650^{\circ} \mathrm{C}$.); moreover, no lumps and scarcely any air bubbles were present. The detalls of the method finally adopted for the preparation of the fusion mixture follow:

Heat a mixture of $9 \mathrm{~g} \mathrm{NaF}, 45.5 \mathrm{~g}$ of $\mathrm{Ha}_{2} \mathrm{CO}_{3}$, and $45.5 \mathrm{~g}$ of $\mathrm{K}_{2} \mathrm{CO}_{3}$ in a large platinum dish in a furnace at $650^{\circ} \mathrm{C}$. for 15 to 20 minutes or until most of the material has fused. Complete the fusion over a Meker burner and swirl the melt until it is well mixed. Fuse as many 100-g lots of the mixture as are desired. Then break up the cakes in a large mortar with a pestle until all of the fused material will pass through a 5-mesh screen. Place the lumps of flux in a dry, warm ball mill, and tumble it for about 3 hours or until the mixture will pass through a 65-mesh screen. Remove the pebbles and again tumble in the ball mill for several hours. Store the stock in a large tight 
Table 7.--Inadequacy of fusion mixture prepared by ball-milling (Fusions made in small furnace at $650^{\circ} \mathrm{C}$. - blank samples)

\begin{tabular}{c|c|c|c}
\hline $\begin{array}{c}\text { Sample } \\
\text { no. }\end{array}$ & $\begin{array}{c}\text { Time required } \\
\text { to melt } \\
\text { (minutes) }\end{array}$ & $\begin{array}{c}\text { Total time } \\
\text { in furnace } \\
\text { (minutes) }\end{array}$ & $\begin{array}{c}\text { Reading } \\
\text { (divisions on 0.02 scale) }\end{array}$ \\
\hline 1 & $3-4$ & 5 & 42.0 \\
2 & $3-4$ & 5 & 39.2 \\
3 & $3-4$ & 6 & 46.0 \\
4 & 10 & 10.5 & 37.8 \\
5 & 8 & 10.5 & $\begin{array}{c}\text { off scale- } 36.1 \text { on } \\
0.05 \text { scale }\end{array}$ \\
6 & 8 & 10.5 & off scale- 23.0 on \\
0.05 scale \\
7
\end{tabular}


bottle. Transfer to smaller bottles as required for use. The mixture is hygroscoplc in damp weather; consequently, when not in use, the containers must be kept tightly closed.

\section{ANALYHICAL PROCEDURE}

The chief differences in the analytical procedure adopted by this Iaboratory and that used elsewhere are:

1. The use of a transmission fluorimeter for the measurement of the fluorescence of the melts;

2. The use of controlled low-temperature fusions with the consequent elimination of standard samples.

Most other laboratorles fuse about 6 standards and several blanks along with the samples for each fusion operation, and prepare a new curve for each set of samples fused.

The equipment used here is shown in figures 4, 5, and 6. FIgures 4 and 5 are photographs of the Model II transmission fluorimeter and D.C. amplifier 17/ which were used for the work described in this report. A Model $V$ has now been built and is described elsewhere.18/ Figure 6 (A) shows the stalnless steel

17/ Fletcher, Mary H., May, Irving, and Slavin, Morris, A transmission fluorimeter for use in the fluorimetric method of analysis for uranium: U. S. Geol. Survey Trace Elements Investigations Rept. 104, August 1949 .

18/ Fletcher, Mary H., May, Irving, and Anderson, Joseph W., The design of the Model V transmission fluorimeter: U. S. Geol. Survey Trace Elements Investigations Rept. 133, December 1950. 


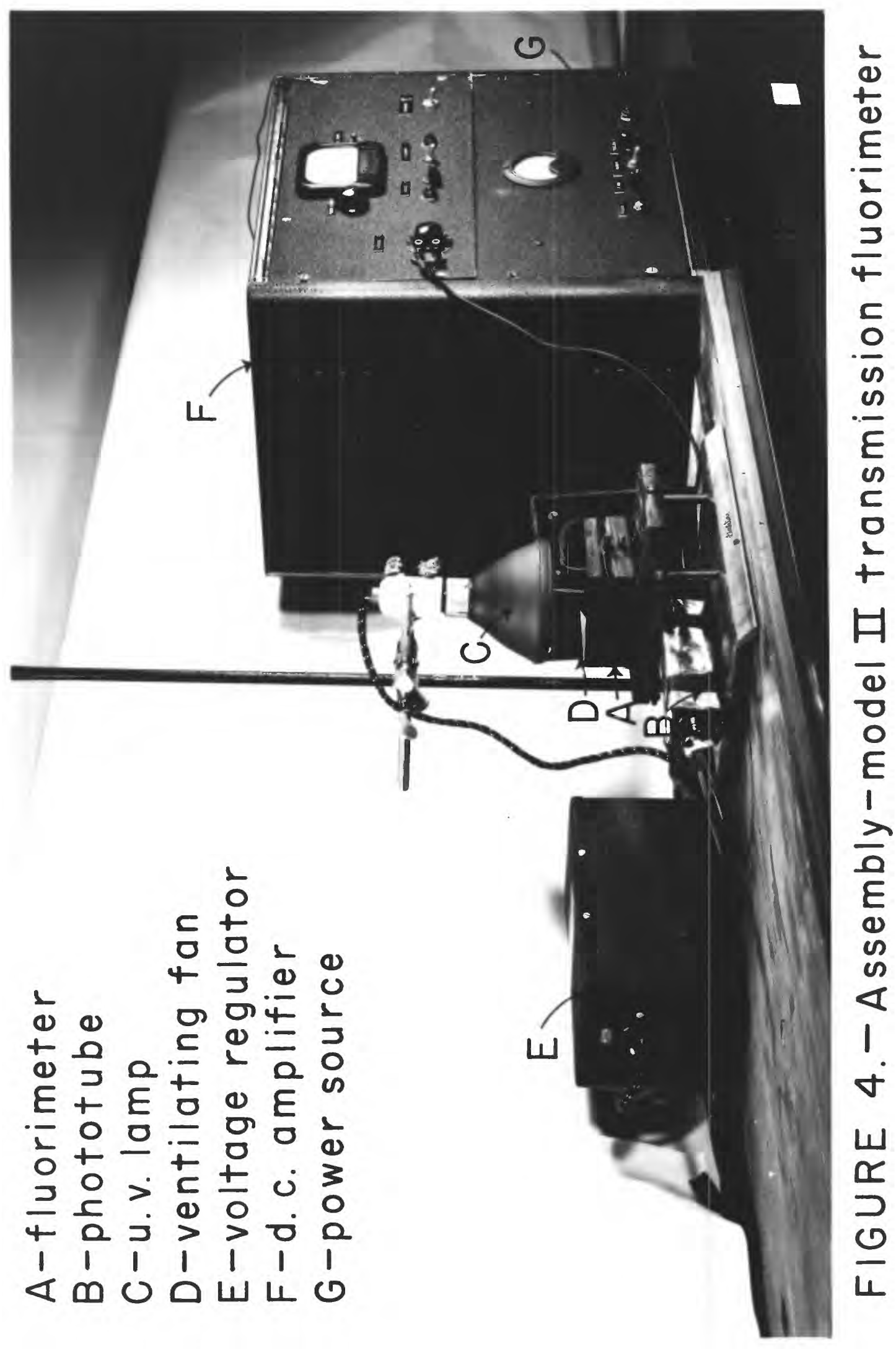




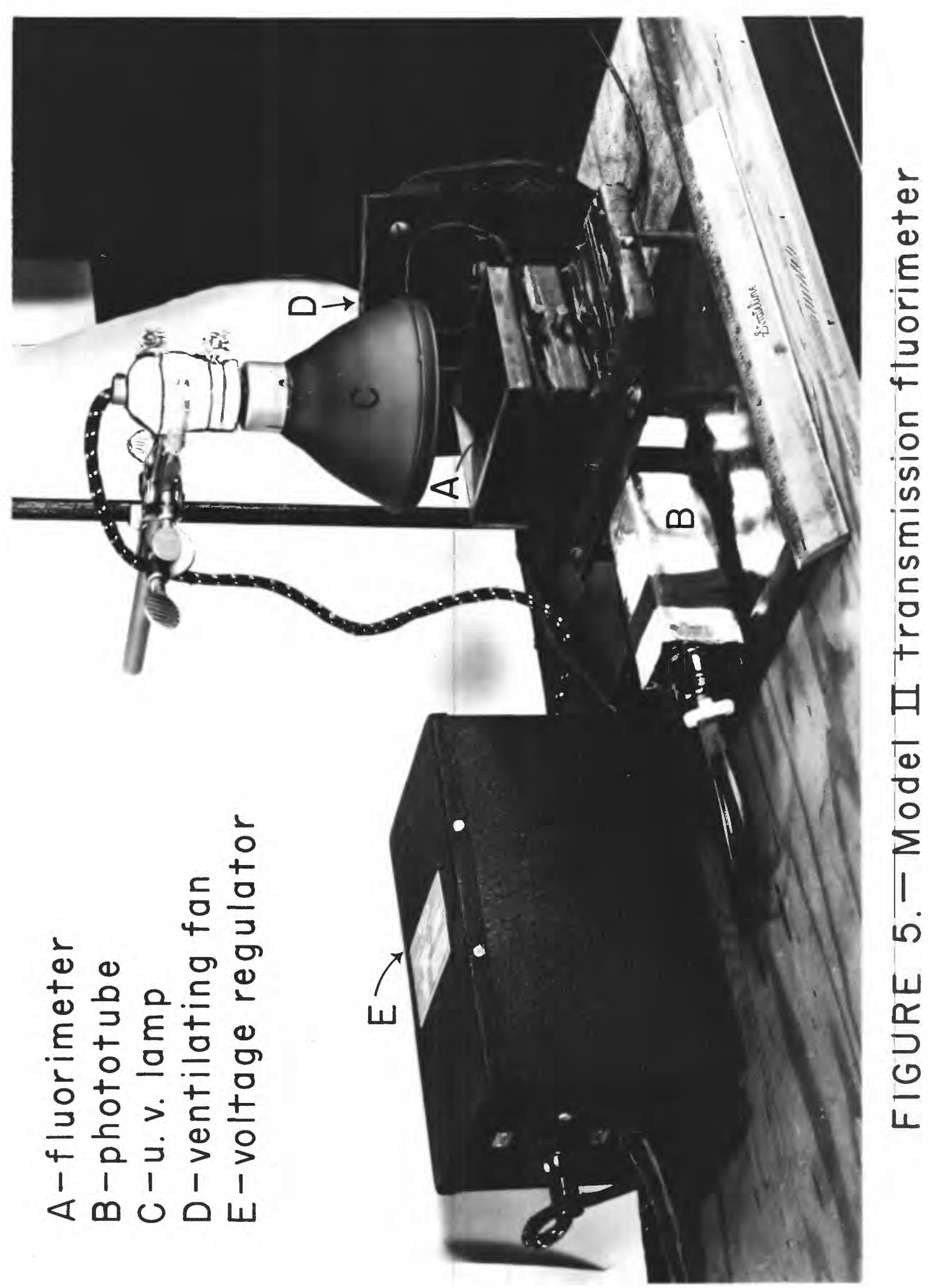



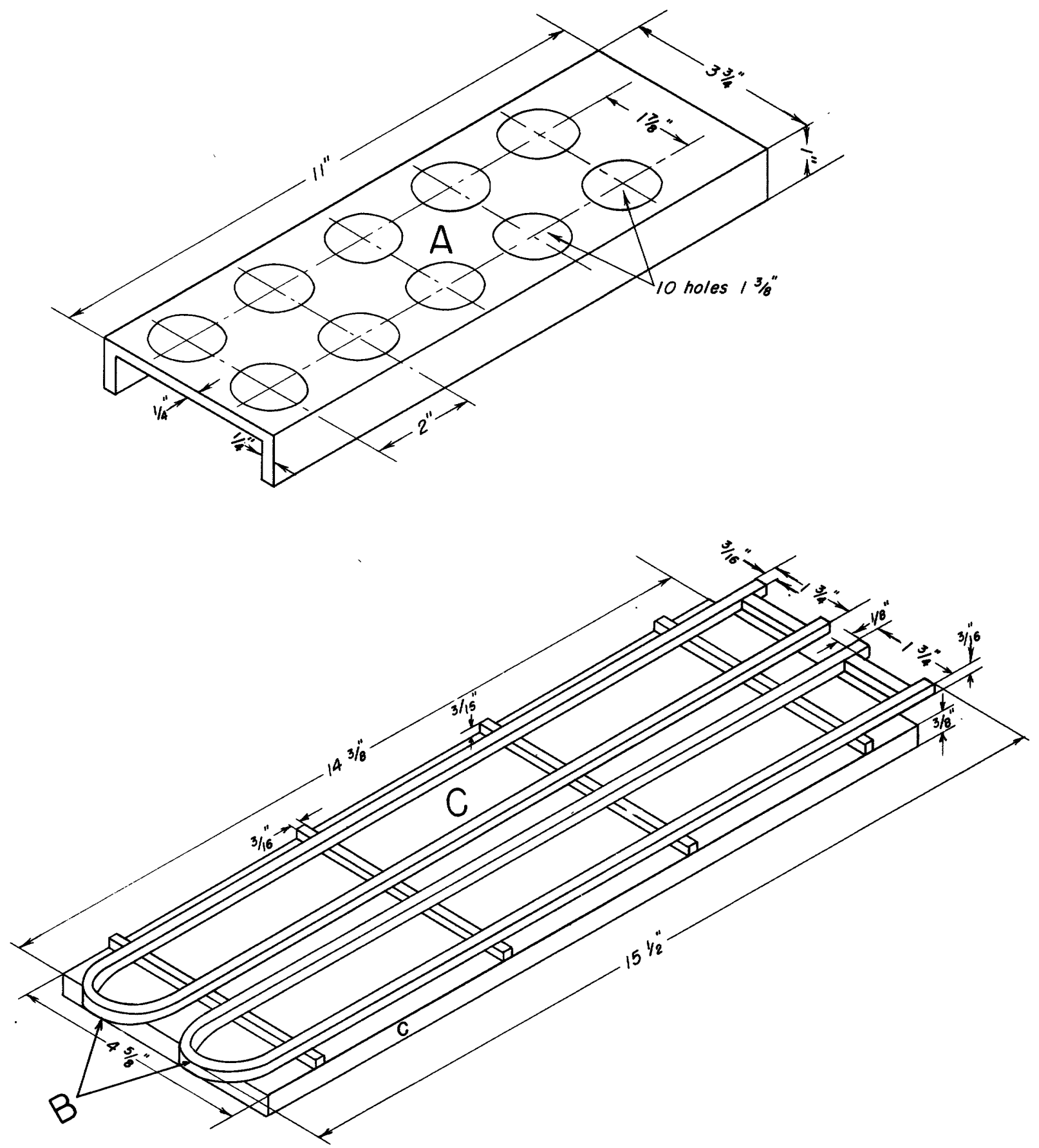

Figure 6-Equipment 
racks that hold 10 lids each. The lids are placed on these racks, the sample solutions pipetted onto the lids and dried in place on the racks. Figure 6 (B) shows chromel racks made from furnace heating elements which are used to hold the lids in the furnace during the fusion period. Figure 6 (c) shows a transit plate with attached chromel rods which is placed on the bottom of the furnace to serve as a support for the racks and samples during fusion. The sample solutions are transferred to the lids with graduated 0.2-ml pipettes. The platinum lids are from 25-ml crucibles.

For the determination of the uranium in any sample, a small amount of the sample was weighed onto the lid, or a small amount of the sample solution was pipetted onto the lid. When liquid, the sample was dried under an Infrared lamp or on a hot plate, and ignited briefly. For both solids and liquids, $1.5 \mathrm{~g}$ of fusion mixture was added to the lid. The lids were transferred to the chromel racks and placed in the furnace, which was set for $650^{\circ} \mathrm{C}$; the samples were allowed to remain in the furnace for 25 minutes. During this period they were mixed three times by shaking the racks gently. At the end of 25 minutes the racks and lids were removed from the furnace. The lids were placed in a desiccator and allowed to cool 30 minutes; after this period the fluorescence of the melts was measured.

The size of the sample used for the final determination, and the methods of preparation of the sample solution are flexible and are determined by the nature of the sample and the quantity available. For average samples, the final aliquot was chosen to contain 0.001 to 0.08 
micrograms of uranium, and usually represented 50 micrograms of sample although both much smaller and mach larger samples have been successfolly used.

When the amount of sample is limited, the uranium content low, ". and the amount of quenchers negligible, the solid sample can be used directly. For example, with plant-ash samples that contain from a few hundredths of a part per million to a few parts per million of uranium and only swall amounts of quenching elements, $5 \mathrm{mg}$ of the solid sample are fused directly. When the sample is readly soluble in acid, 50 mg are weighed into a flask, $100 \mathrm{ml}$ of 18 percent Hilo 3 measured into the flask, the flask covered with a watch glass and heated until it just boils. It is then cooled and a 50-mierogram (0.10-ml) aliquot is pipetted onto the lid, and the determination continued as outlined. Samples which are not readily soluble in acid usually are decomposed by fusion with a mixture of $\mathrm{Ha}_{2} \mathrm{CO}_{3}$ and $\mathrm{Na}_{2} \mathrm{~B}_{4} \mathrm{O}_{7}(4+1)$. This flux has the advantage of keeping silica in solution. For decomposition with the carbonate borax flux, 10 to $50 \mathrm{mg}$ of the sample are weighed into a small platinum crucible and fused with $500 \mathrm{mg}$ of the flux. The crucible then is placed in a 100-ml beaker which contains $30 \mathrm{ml}$ of 30 percent HCl, and the beaker is placed on a hot plate for a few minutes. The fusion melt dissolves in about 3 minutes to give a clear solution. When the melt is completely dissolved, the cracible is removed from the beaker and rinsed with water. The solution is transferred to a 100-ml volumetric flask and diluted to volume. (Further dilutions of this solution are made if the percentage of uranium in the sample is greater than about 0.1 .) A $0.1-\mathrm{ml}$ aliquot then is taken 
for the determination. Hydrochloric acid instead of nitric acid was used to prepare these sample solutions because there is danger of attack on the platinum by $\mathrm{NaHO}_{3}$, and less creeping of the borate residue occurred with hydrochloric acid. An aliquot of $0.1 \mathrm{ml}$ of sample solution was chosen because it evaporates quickly and the residue is confined to a small spot; thus the flux is always in contact with the sample during fusion.

The lids used for the determination are cleaned by acid washing. The melts are removed, and the lids boiled for a short time in 1:1 HCl to which a few milliliters of HF have been added. The acid then is drained off, the lids rinsed with water, and boiled once or twice again with 1:1 HCI. After this they are rinsed well with distilled water, and dried over a bunsen burner.

\section{RESULTS}

Results of determinations carried out by this method are given in tables $8,9,10$, and 17 . In table 8 the results of replicate analyses on standard shale sample GST-I are given. The average amount of uranium found was 0.0087 percent $U$ with an average deviation from the mean of 0.00018 percent $U$. The average amount found by six laboratories was 0.0086 percent $U \pm 0.00017$ percent $U$. Table 9 shows the results on the standard shale sample GST-2. The percent uranium found was 0.0127 percent $U$ with an average deviation from the mean of 0.00038 percent $U$, whereas the average value from six laboratories was 0.0123 percent $U$ \pm 0.00008 percent $U$. Table 10 gives comparative determinations of 
uranium by the "direct" method, by the extraction procedure, 19/ and by radiometric count. Each result represents a single determination. The correlation is good. Table 11 shows comparative results for determinations by the "direct" method using 100- and 20-microgram aliquots. Bach value again corresponds to a single determination, and the results agree.

\section{CONCLUSION}

The method as outlined has sufficient sensitivity and accuracy to determine a few thousandths of a percent of uranium in a $0.02-m g$ sample. Through the use of small aliquots, quenching from foreign ions is reduced to a minimum, and chemical separations generally are unnecessary. Lowtemperature fusions eliminate platinum quenching. Standards of any kind are unnecessary once the standard curve has been prepared. The method is especially useful where the amount of material is small, and it is invaluable where the sample is small and the uranium content is low.

19/ Grimaldi, F. S., and Levine, Harry, The rapid fluorimetric determination of uranium in low-grade ores; a preliminary report: v. S. Geol. Survey Trace Elements Investigations Rept. 47, April 1948. 
Table 8.--Replicate analyses of standard shale sample GST-1 I/ Uranium present 0.0086 percent \pm 0.00017 percent $U$ (100-microgram aliquots of sample)

\begin{tabular}{c|c|c}
\hline Replicate no. & $\begin{array}{c}\text { Uranium found } \\
\text { (micrograms and percent) }\end{array}$ & $\begin{array}{c}\text { Deviation from mean } \\
\text { (micrograms and percent) }\end{array}$ \\
\hline 1 & 0.0085 & 0.0002 \\
3 & 0.0085 & 0.0002 \\
4 & 0.0088 & 0.0001 \\
5 & 0.0088 & 0.0001 \\
6 & 0.0088 & 0.0001 \\
7 & 0.0088 & 0.0001 \\
8 & 0.0091 & 0.0004 \\
9 & 0.0086 & 0.0001 \\
10 & 0.0081 & 0.0006 \\
11 & 0.0086 & 0.0001 \\
12 & 0.0088 & 0.0001 \\
mean & 0.0088 & 0.0001 \\
\hline
\end{tabular}

1/ See table 5, p. 13, "A transmission fluorimeter for use in the fluorimetric method of analysis for uranium," by Mary H. Fletcher, Irving May, and Morris Slavin, U. S. Geol. Survey Trace Elements Investigations Rept. 104, August 1949. 
Table 9.--Replicate analyses of standard shale sample GST-2 Uranium content 0.0123 percent \pm 0.00008 percent $U$ (100-microgram aliquots of sample)

\begin{tabular}{c|c|c}
\hline Replicate no. & $\begin{array}{c}\text { Uranium found } \\
\text { (micrograms and percent) }\end{array}$ & $\begin{array}{c}\text { Deviation from mean } \\
\text { (micrograms and percent) }\end{array}$ \\
\hline 1 & 0.0133 & 0.0006 \\
2 & 0.0128 & 0.0001 \\
3 & 0.0128 & 0.0001 \\
4 & 0.0120 & 0.0007 \\
mean & 0.0127 & 0.00038 \\
\hline
\end{tabular}


Table 10.--Comparison of results obtained by different methods of analysis of northwest phosphates

\begin{tabular}{|c|c|c|c|}
\hline \multirow{2}{*}{ Sample no. } & \multicolumn{3}{|c|}{ Percent uranium found } \\
\hline & $\begin{array}{l}\text { "Direct" method } \\
\text { 100-microgram } \\
\text { al1quot }\end{array}$ & $\begin{array}{l}\text { Extraction } \\
\text { 3.6-milligram } \\
\text { aliquot }\end{array}$ & Radiometric count \\
\hline 1 & 0.009 & 0.010 & 0.011 \\
\hline 2 & 0.008 & 0.007 & 0.009 \\
\hline 3 & 0.010 & 0.008 & 0.009 \\
\hline 4 & 0.010 & 0.010 & 0.011 \\
\hline 5 & 0.007 & 0.007 & 0.008 \\
\hline 6 & 0.004 & 0.004 & 0.006 \\
\hline 7 & 0.013 & 0.013 & 0.013 \\
\hline 8 & 0.011 & 0.010 & 0.013 \\
\hline 9 & 0.008 & 0.008 & 0.008 \\
\hline 10 & 0.010 & 0.008 & 0.010 \\
\hline
\end{tabular}


Table 11.--Determination of uranium by the "direct" method using different aliquots

Samples no. I through 12 are Florida phosphates

Samples no. 13 through 20 are northwest phosphates

\begin{tabular}{|c|c|c|}
\hline \multirow[t]{2}{*}{ Sample no. } & \multicolumn{2}{|c|}{ Percent uranivm found } \\
\hline & 100-microgram al1quot & 20-microgram aliquot \\
\hline 1 & 0.023 & 0.022 \\
\hline 2 & 0.005 & 0.007 \\
\hline 3 & 0.012 & 0.015 \\
\hline 4 & 0.009 & 0.008 \\
\hline 5 & 0.012 & 0.013 \\
\hline 6 & 0.010 & 0.010 \\
\hline 7 & 0.010 & 0.010 \\
\hline 8 & 0.007 & 0.011 \\
\hline 9 & 0.016 & 0.015 \\
\hline 10 & 0.006 & 0.006 \\
\hline 11 & 0.013 & 0.014 \\
\hline 12 & 0.017 & 0.019 \\
\hline 13 & 0.013 & 0.013 \\
\hline 14 & 0.008 & 0.008 \\
\hline 15 & 0.010 & 0.007 \\
\hline 16 & 0.013 & 0.012 \\
\hline 17 & 0.009 & 0.009 \\
\hline 18 & 0.013 & 0.014 \\
\hline 19 & 0.006 & 0.006 \\
\hline 20 & 0.013 & 0.013 \\
\hline
\end{tabular}

